\title{
Unmanning in Military Field and the Future of Infantry Branch: A Case Study of Turkey and the US
}

\author{
Ercan Karakoc ${ }^{1}$, Osman Yildiz
}

Assoc. Professor, Yildiz Technical University, Istanbul, Turkey

Graduated MA Student, Gebze Technical University, Gebze, Turkey

\begin{abstract}
Computer technologies, improved in the lights of space studies that is started after World War II affects many field, it is assumed as a start of unmanning as well. Unmanned vehicles sent into space made it possible to use these technologies in the earth. Thus, it is assumed that technology of processor will have been able to arrive the capacity of the way that human brain processes by 2030s. Especially, the heavy losses of countries and so the nation during the Second World War, increased the importance of unmanning that the big states gives on the military field, have caused them to focus on this field. Armies have started the regime of the skilled and professional staff that will be able to use the technology imparted with the unmanning, in conclusion of this; they have given more importance of the infantry branch. In this respect, the capacity of the infantry branch, which is the oldest military branch, has increased and the other military branches that has been parted from the infantry branch in the last century has turned out to be planned being inserted in the infantry branch. Nowadays another reason for that of the infantry branch has become important, is that people has started to live mostly in cities. It is estimated that the percentage of world urbanization which was $\% 60$ in 2010s, will have been $\% 80$ by 2030s. In this study, it will be examined how the unmanning in military field shapes the infantry branch and Turkey will compare with USA which is the leading force about unmanning.
\end{abstract}

Keywords: Unmanning, Infantry, Unmanned Ground and Aerial Vehicles, Satellite Technology, Laser Guided Bomb.

\section{INTRODUCTION}

The process of industrialization has begun in the 1800s, and also brought mechanization together with it. As the machines provide great easiness to the humanity in either civilian or military parts, it has increasingly expanded along with the 20th century. In the 1960s, technology of computer has begun to be used during the space studies which has deeply influenced on the process of mechanization, and were used within a system where computers and machines complement to each other. In fact, according to Moore's $1 a^{2}$, in the 2030's, the technology of computer processor will be able to have access almost to the capacity of the human brain. When it is considered from this point of view, the computer will be replaced with the ones which are to be learned and applied in the future rather than the today's computers which are only be able to carry out the given commands. Increasing capacity and downsizing the physical size of the processor, has begun to be noticed in the military field, even the most basic weapons systems have provided opportunities to have smart technology. In this context, the war increasingly starting to be executed in the city, serious causes such as failure welcome to the human casualties in national public opinion and the complexity of the task led the governments to unmanning in the military field.

During The First World War, the short-ranged managed with wire, so-called the primitive, when unmanned systems or aircraft models are not taken into account; in 1930's, DH-82B Queen Bee ${ }^{3}$ aircraft was used by the British Royal Navy and directed by the use of radio frequency that can be expressed as the first unmanned vehicle in the unmanning literature. In oncoming years, along with the usage of global positioning system

\footnotetext{
${ }^{1}$ Corresponding Author:ercankarakoc@hotmail.com

${ }^{2}$ The founder of the Intel company, Gordon Moore, has the form of a statement in a magazine in 1965, "the number of transistors in microprocessors will double every 24 months ...". For more information, see http://www.intel.com/content/www/us/en/history/museumgordon-moore-law.html. (Access Date: 14/02/2015)

${ }^{3}$ Sperry Aerial Torpedo produced in the US in 1910 and V-1 produced in Germany in the 1940s, although, some experts expressed them as to be the first unmanning vehicles, however these properties can be defined as a bomb due to their characteristics appearances. For more information, see http://www.pbs.org/wgbh/nova/spiesfly/uavs.html. (Access Date: 02/11/2015)
} 
(GPS), the first unmanned aerial vehicles have begun to be used for exploration missions in the First Iraq War. Changing the course of unmanned vehicles of the war in Afghanistan during 2001 and, the war in Iraq during 2003, was a case occurred during the war. Laser-guided bombs accurately can hit the five meters target, increasing efficiency with minimizing volume activity and transmitting images of satellite technology in a second within a short delay, unmanned vehicles were led to be used by the developed countries, especially the United States during their operations. The triangle of Satellite, GPS and laser-guided bombs are completed by the states with their own expenses, that unmanning accepted to be the pioneer in the military field. In this regard, when the dominant states in the world, the US, Russia, China, France and the UK compared with each other, the US stands out to be ahead than others regarding the unmanning issue in the military area. As France has enough technology but that cannot be considered to be a pioneer country, as the British technology is dependent on the US, as China and Russia do reverse engineering for unmanning process.

Unmanning and technological developments are also profoundly influencing on infantry branch that is the oldest military branch in the history. The complexity of the battlefield which is executed in the cities is minimizing the size of infantry. Other military branches such as artillery and tank staff are being forced to be involved in the organization of the infantry. The unmanned air and ground vehicles are also presented in order to be used by infantry branch. That shows in the future, infantry branch will be the most important branch of land forces.

\section{OVERVIEW OF UNMANNING}

When human history is analyzed, unmanning mania can be considered to start with the Industrial Revolution in the 1800s. When the mechanization takes the labor place of industrial plants, some business in the need for labor was met by machines. Machines, rather than do any work on its own, into which was inserted into the man-made system, and an intermediate element of human nature that directed these tools. Nearly a half century after the Industrial Revolution, machines with capable of its own have begun to emerge that assigned duties in certain limits. When Computer and technology of the processor started to be used with the machines, these machines were also named as "unmanned". For example, a dozer is a machine which is used for the constructions. However, when a computer mounted to these dozers and programmed to what to do, the dozer ceased to be a machine and can be restored into "unmanned dozers". In recent years, computer, communications, and computer integrated machines with electronic systems, became pioneering the development of robotic systems and reduced the production costs. This transformation in the robotic system has shown itself in the business world, the consumer market, and the education system as well as the military field (Tsourveloudis et al., 2005).

The number of robots in the world increases every day and the price is reduced in inverse proportion. Robot price is $80 \%$ cheaper in 2006 compared to the year of 1990. Today, it is possible to make an unmanned aerial vehicle (UAV) for almost $£ 250$ (Quintana, 2008).

In 2006, the owner of Microsoft Corporation, Bill Gates wrote an article with the title of "A Robot in Every Home" in an article in which robots, will be widely used in difficult profession or business areas such as construction, surgery and military that people have difficulty to see or have difficulties in the future. Gates stated 30 years ago that no one would regard it possible when it is told that each home will have the computer, it also should not be underestimated that the possibility of every home would have the robot in the future (Sklar, 2010).

The civil use of unmanning systems typically include: Atmospheric and geographical surveys, mapping, mineral exploration, police surveillance, border security, security of energy lines, traffic safety, the surveillance of disasters, search and rescue, agricultural spraying and fire surveillance etc. The human factor may disappear in all agricultural activities in the future such as seeding process with unmanning of agricultural machinery, the process of harvesting and irrigation products (Jones, 2009). Another application section of robot is the medical sector. In the future, robotic surgical system is managed by remote doctor will be taken place with a delay of up to $\% 1$ of a second surgery in a fully sterile environment (Chiang and Wrightson, 2012). Time will show whether the robots or the doctors are more sensitive in surgery and whether the people can trust the robots or not.

According to Bessemer, the majority of transportation and cargo aircrafts in US war will have the unmanned systems by the 2030 (Bessemer, 2006). The studies of turning commercial cargo aircraft into unmanned status are also ongoing situation. When unmanning is obtained, the training of pilots and employment costs to the company will no longer take place.

As it is understood, the effects of the unmanning is not normally felt in our daily life, however it's significance is quite huge. With growing fast and firm step, Unmanning technology, will perhaps show a feature in the future 
that will be felt by the side of the people almost every moment of life. From agriculture to medicine, and from atmospheric research to the safety in many areas of life, robots will become people's work colleague.

Since the beginning of history, people always fought with each other and formed the army for it. The main purpose of scientific research is supposedly to make life easier, often used to improve military technology, that the States turned a portion of the related military technology to the needs of civilians as they want to reduce the cost of production of the system or weapons. The development of unmanning has just started up in the military field as well as in other areas.

The invention and use of robots, is the biggest revolution since the invention of gunpowder emerging in the field of battle technology. The use of robots is also seen as a threshold in the history of war (ARLTAB, 2011). The use of Robots in the war of Afghanistan in 2001 and Iraq in 2003 constitutes a revolution in the history of warfare. The size, design, talent and in the terms of autonomy of future war, will be executed among different robots as it is foreseen in advance (Larkin, 2011). The States have begun to grasp the importance of robots in the military field.

Bessemer has expressed that how important of robots in the winning or the lost war which follows as: "Imagine an army who has the world's most advanced weapons systems and ammunition. Only consisting of robots; and consider another army who has the ten thousand robots on the land, air and sea. The army with man will probably win the battle $80 \%$. However, 500 thousand corresponds to the human casualties, the enemy who has not lost any people; does that mean you win the war?" (Bessemer, 2006).

Unmanned vehicles are simply designed to be used in three types of military duty:

1. Dangerous Missions: Missions can be entered into substantial risk of human life. Reconnaissance operations in Iraq and Afghanistan can be given as examples of these missions.

2. Dull Missions: These missions are long-term reconnaissance and surveillance missions that when people do it, they will be distracted after a certain period of time. Border security tasks are like these types of missions.

3. Dirty Missions: This type of missions are called dirty missions because; it can be very difficult and dangerous for people to detect and make discoveries due to nuclear, chemical or biological agent in contaminated areas. Exploration missions in nuclear installations can be shown as an example (Neal, 2010).

According to Guest, in 2020, the enemy should not be expected to have a fight with industrial age tools (Guest, 2011). Soldiers will fight with advanced technological equipment in future. According to Nader, for the US largest development for marines is to adapt the unmanned systems into their systems (Nader, 2007). As it is understood, unmanning is a very important threshold in the creation of the army of the future. The states will likely fail in future wars if not blended with Manned and unmanned systems. It is certain that even if they are successful, they will still face heavy losses.

\section{THE EFFECTS OF UNMANNING ON INFANTRY BRANCH}

Nowadays, whenever unmanning is mentioned, unmanned aerial vehicles come to people's mind. But the studies of armies for infantry branch are in progress. Unmanning of the United States Army in the terms of the infantry branch is centered on the production of unmanned ground vehicle (UGV) and four types of unmanned ground vehicle platforms.

These platforms consist of four types according to their abilities:

1. Tracked UGV,

2. Semi-tracked UGV,

3. Wheelchair UGV,

4. Legged UGV (Yuqiao, 2009).

The studies relating to the UGV production comprise two main processes. These are:

- the production of robotic legs system to walk on land,

- the process of turning vehicle platform into unmanned vehicle platform.

UGV is the first production process that was begun in the 1960s along with the robotic leg system of R\&D activities. A machine is named as "walking truck" which is manufactured by Ralph Mosher in R\&D laboratory of the General Electric Company in 1968 (Sklar, 2010). This system was used by the operator with the help of four arms and four pedals. Such systems can be regarded as a turning point in today's technology that is required for pedestal systems to produce the land robots, although not defined as an unmanned system. Some research has been conducted for the US Armed Forces in the 1980s; the fruit of the leg laboratory was able to 
present in our days, even though, it has been exercised in Carnegie Mellon University (CMU) Leg Laboratory, followed by Massachusetts Institute of Technology (MIT). Some of the companies such as Boston Dynamics are currently known to produce walking robots. Four-legged robot, Big Dog is produced by the Boston Dynamics company and it has the ability to run and climb the difficult terrain. An advanced computer system can direct the internal system to analyze data which is sent by the sensor in Big Dog's walking, running and included in the system. It works with a liquid fuel. It would be appropriate to mention here that the robotic exoskeleton system is expected to be common in the future with the production of robotic legs. The US based Lockheed Martin and Raytheon companies, have developed exoskeleton system with a computer and sensor systems that has the two legs, entering into motion and expressing exactly like human being (BAST, 2013). It is currently in the testing phase and expected to be used commonly by infantry branch for a long task once the energy issue will be solved. The second process relates to turn vehicle platform into unmanned vehicle platform. XM-1219 Black Knight and HR platform are the best two examples of vehicle platform. With antitank weapons and machine guns of XM-1219, which can provide close support to the infantry in battle and it is based in the US with a weight of 2.5 tones. Some advantages are provided for XM-1219 due to having wheeled platform, to be used in urban warfare. Black Knight is another system with 12 tones, which is an unmanned ground vehicle platform that can be transported by C-130 aircraft (Valois et al., 2009). It can also be used like a manned vehicle as required. Black Knight is foreseen as unmanned ground vehicle for the mechanized infantry of the future. The system with four stereo camera and numerous sensors has a cannon and machine guns.

Apart from producing unmanned ground vehicles, the US is also planning to configure land forces in accordance with unmanning system. For example, UGV's in the US military will gradually be included into the infantry branch organization. According to a study of Army Science and Technology Board which conducted in 2002, UGV of the infantry branch in four phases are foreseen to be included in the organizational structure (BAST, 2002). The first stage of UGV as an investigator will be gradually assigned as a separate union from the military in order to discover of the region. This vehicle in this process is controlled manually from a distance with remote control units in the perspective of the troop. The second stage of the UGV as a mule is planned to carry the load of duties undertaken by the troops. This vehicle at this stage will be able to perform the visual operations within a certain range of frequency. The third stage is called as the stage of UGV as a wingman. At this stage, UGV is planned to participate with the military union against the possible conflict by going through the same area in the semi-autonomous levels. The final stage of the UGV as a hunter is that UGV is to be planned to control the area and comes into contact with the enemy as apart from the troop if necessary. The vehicle may be given an independent task the so-called worthy task, due to having a vehicle with fully autonomy planned in this stage.

As it is understood, it is obvious that unmanned ground vehicles will create much more effect than unmanned aerial vehicles in the battlefield even though the history of the development of unmanned ground vehicles is not as old as the unmanned aerial vehicles. Because in the city; unmanned ground vehicles will be only vehicles to deal with people from the residential locality in the war, to the police of residential neighborhood in the future. In addition to this, it would not be wrong to predict the unmanning process which initiated the development of the infantry battle will determine the fate of the land. As it can be anticipated in today's technological advances that there is a little time left for the movie to take place in the science fiction genre, which implies a "Terminator".

\subsection{Historical Development of Infantry Branch on Personnel Regime}

Infantry simply means "the pedestrian soldiers". The infantry branch always continues to show itself in the battlefield, although there have been some changes in various historical periods. The process of the infantry's assignments in the battlefield is gradually shown in Table 1. Here, the general terms of use of the infantry are taken into account rather than the country or the war.

Table1. The Assignment Process of Infantry Troops in the Battlefield.

\begin{tabular}{|c||c||l||}
\hline \multicolumn{1}{|c||}{ Stages } & Historical Period & \multicolumn{1}{|c|}{ Characteristic } \\
\hline \hline First Stage & BC 500- AD 1800 & Local Infantry Units \\
\hline \hline Second Stage & $1800-1960$ & Compulsory Military Service \\
\hline \hline Third Stage & $1960-$ Nowadays & Professional Infantry Troops \\
\hline Fourth Stage & 2020 and Future & Hybrid Infantry Troops \\
\hline
\end{tabular}

According to this table, local the pedestrian troops are formed of infantry troops in the first stage with lower 
administrative units regarding feudalism, education, called by size, clan and tribe during wartime. This stage began in BC 500 covers nearly the beginning of the 1800 s, a time until the industrial revolution. Infantry units in this period can be called local infantry units that the army of infantry needs is met by the local government units. However, the salary of some states has been allocated from the central budget such as Rome and the Ottoman Empire, and some of them had a permanent residence in the barracks.

The second stage is formed by the infantry units with mandatory military nature and the governments that provide and create shelter and educational opportunities for the infantry barracks. The second stage began in 1800 's and continued throughout the world until the 1960s. Army infantry units in this period who may be called compulsory military service personnel with infantry troops that the infantry's needs is to be met by the general of the country.

Infantry troops in the third stage; constituted of professional infantry troops that the military service which was turned into a profession in the period and the compulsory military administration removed by the governments. This stage began in the 1960s, a stage which is still continued by many governments nowadays. For example, England in 1960, the United States in 1973, France in 2001 and Italy in 2004; they all have switched their system into a professional army system. In Turkey, the compulsory administration of military service is still in force, and the time period is between 6 to 12 months (Akyurek, 2010). Infantry units can be called professional infantry troops in this period and the army infantry requirements are met on a voluntary basis.

The fourth and final stage of infantry troops will be formed in the use of robots and robot systems for the organization of infantry. As the commencement date of this phase is not fully anticipated however, it will begin in the year 2020 and it is expected to be spreading in 2040's. This stage is involved in the process of unmanning stage that is a stage of hybrid infantry troops.

It is understood that the infantry troops have changed their restructuring in various historical processes according to changes in needs of nature of the war and the country.

\subsection{The stages of unmanning in military}

We can qualitatively examine the process of the unmanned in the military field in five stages. These stages respectively follow as; the use of radio frequencies to guide unmanned vehicles, the use of satellite technology, the laser-guided bombs are to be used as the complementary elements of unmanned vehicles, the experiencing of diversification of unmanned process and full autonomy owner is taking its place in the battlefield of unmanned systems. The unmanning process in the military field is shown as stages on Table 2.

Table2. The Unmanning Process in the Military

\begin{tabular}{||c||l||}
\hline \multicolumn{1}{|c||}{ Unmanning Stage in Military Field } & \multicolumn{1}{c|}{ Characteristic } \\
\hline \hline First Stage & The Usage of Radio Frequency \\
\hline \hline Second Stage & The Usage of Satellite Technology \\
\hline \hline Third Stage & $\begin{array}{l}\text { The Usage of Laser Guided Bombs as a } \\
\text { Complementary Effect }\end{array}$ \\
\hline Fourth Stage & $\begin{array}{l}\text { The Diversification Process of the Unmanning } \\
\text { Systems }\end{array}$ \\
\hline \hline Fifth Stage & $\begin{array}{l}\text { The Usage of Unmanned Systems with Fully } \\
\text { Autonomy }\end{array}$ \\
\hline
\end{tabular}

According to the table above, the unmanning in the military field began with primitive model in the early 1900s and began to develop with the DH-82B Queen Bee aircraft which was directed by the radio frequency and used by the British Royal Navy in 1930's. In later years, even though the aircraft directed with radio frequency that produced in the same way, this aircrafts were accepted as model aircraft due to the low range of frequency bands and discontinuation of the sudden waves. Unmanning process in the military field, the use of radio frequency is evaluated as the first stage.

The satellite technology has expanded with the "Space Race", as it began with the launch of Sputnik-1 satellite of Soviet Union in the year of 1957, and the satellites are being used with it for military purposes. Having unmanned vehicles to be dependent of radio frequency, has been expired due to using with GPS technology also with it being dependent on the satellite technology, thus, operational range of unmanned vehicles have been increased. The use of satellite technology can be considered as the second stage during the unmanning process in the military field. 
American Research Journal of Humanities and Social Sciences, Volume 1, Issue 4, 2015 ISSN 2378-7031

In the 1980s, the unmanned process with having an accessed into a specific quality; has become manifested itself more with the production of unmanned aerial vehicles and the acceleration of the survey on walking robot on the land assigned for discovery in the air. The various models of UAVs can be given as an example for this as they were used by the US in the Iraq war in 1991 and the Israel in 1980. The laser-guided bomb technology was used for the first time at the end of the 1990s, and has created a complementary effect on the unmanned aerial vehicle as proving the success of the operations in Afghanistan in 2001and Iraq in 2003. The unmanned vehicles were turned into fighting machine by removing their character as a discovery tool, as the technology of laser-guided bombs were used with the unmanned vehicles during unmanning process. Laser-guided bombs can be regarded as the third stage as they were used along with unmanned vehicles.

When the year of 2010s arrived, Predator with a quality of "propeller plane", Reaper and similar model of UAVs didn't satisfy the governments during the unmanning process. The production processes of unmanned systems have been accelerated in the sea and submarine; jet-powered unmanned air jets; the robots which are able to walk on the land. For example, all kinds of movable Big Dog land robots in the field, the X-45 and X-47 unmanned jet aircraft, Piranha models unmanned sea surface vehicle and Sea Stalker models unmanned submarines are some projects that matured by the United States during this period. It can be expressed as the fourth stage or the diversification process of the unmanning system which has been diversified through designing vehicles of the land, the sea and the submarine and together with the unmanned aerial vehicles of governments during the unmanning process.

The systems which are capable of making a decision and being able to move on its own in some degree of autonomy that has been started to be designed with the development of computer technology, defined as "autonomous". The systems with fully autonomy are likely to be produced by 2030's. The unmanned systems with fully autonomy, are used together with the developing processor technology during the unmanning process can be referred to as the fifth and the final stage.

When the unmanning is expanded in the military field, it has changed the way the troops were used just as the way the military doctrines were affected. As the unmanned aerial vehicles "successfully" fulfilled the task of the so-called as "dangerous", is evidence that the future of the air force could be entrusted to the unmanned aerial vehicles. The countries are becoming the owner of the naval in order to ensure the safety for the coastal trade routes at sea by the submarine, and in particular the obligation of the marines. The obligation of keeping marines at the sea especially in submarines can be eliminated when these tasks given to the unmanned naval and the submarines.

Using the unmanned systems on the land is a complex issue. The people who start living in cities along with the process of industrialization have led the battlefield to be shifting into the residential neighborhoods. The autonomous legged or wheeled robots can be used in urban areas that are revealed to have the morality issue in the future as they are authorized to kill people. The autonomous robots can also be used as the police apart from the organization of land forces, can restrict people's freedom, can pass into the hands of terrorists and as a result it can be predicted as it can create serious danger to humans. Therefore, in the "land" areas of the future, even though using robots which obeys and take orders are considered to be more reasonable way rather than using the autonomous robots however the governments remains unclear to what extent they will accept this.

\subsection{The unmanned infrastructure of Turkey and the US, the comparisons in terms of the characteristics of infantry branches}

In the previous sections, the processes of unmanning in the military field and the assigning the infantry units in the battlefield were examined. In this section, Turkey and the United States, the unmanned infrastructure in the military field were compared in terms of the characteristics of the infantry classes. As shown in Table 3; Turkey and the US are evaluated in terms of the stages of assigning the infantry units into the battlefield and the status of satellite technology, whether they have a national GPS system, the laser-guided bomb technology and supercomputing infrastructure or not, the unmanned stages in the military field, in which areas of the unmanning they give importance to and so on. 
American Research Journal of Humanities and Social Sciences, Volume 1, Issue 4, 2015

ISSN 2378-7031

Table3. The Unmanned Infrastructure of Turkey and the US and the Comparisons In Terms of the Characteristics of Infantry Branches

\begin{tabular}{|c|c|c|c|c|c|c|c|}
\hline COUNTRY & $\begin{array}{l}\text { SATELLITE } \\
\text { TECHNOLOGY }\end{array}$ & $\begin{array}{l}\text { NATIONAL } \\
\text { POSITIONING } \\
\text { SYSTEM }\end{array}$ & $\begin{array}{c}\text { LASER GUIDED } \\
\text { BOMB } \\
\text { TECHNOLOGY }\end{array}$ & $\begin{array}{l}\text { SUPERCOMPUTING } \\
\text { INFRASTRUCTURE }\end{array}$ & $\begin{array}{l}\text { UNMANNING STAGE IN } \\
\text { MILITARY FIELD }\end{array}$ & $\begin{array}{l}\text { WHICH SYSTEM IS GIVEN } \\
\text { IMPORTANCE TO }\end{array}$ & $\begin{array}{c}\text { THE ASSIGNMENT } \\
\text { PROCESS OF INFANTRY } \\
\text { TROOPS }\end{array}$ \\
\hline TURKEY & DEVELOPING & NOT HAVE & DEVELOPING & $\begin{array}{l}\text { Not have supercomputer in the } \\
\text { Top-500 List }\end{array}$ & $\begin{array}{c}\text { The Usage of Laser Guided Bombs } \\
\text { as a Complementary Effect }\end{array}$ & Aerial Systems & $\begin{array}{l}\text { Compulsory Military Service ( } 6 \\
\text { to } 12 \text { months) }\end{array}$ \\
\hline USA & DEVELOPED & DEVELOPED & DEVELOPED & $\begin{array}{l}\text { Has } 264 \text { Supercomputers in the } \\
\text { Top-500 List }\end{array}$ & $\begin{array}{l}\text { The Usage of Unmanned Systems } \\
\text { with Fully Autonomy }\end{array}$ & Land, Aerial and Naval Systems & $\begin{array}{c}\text { Nowadays; Professional Infantry } \\
\text { Troops } \\
\text { Planning; Hybrid Infantry Troops }\end{array}$ \\
\hline
\end{tabular}

When examining the parameters respectively specified in Table 3;

1. Satellite Technology: Explorer 1 defined as the first US satellite, which took place between the US and USSR in the initial period of "Space Race", it was launched into space in 1958. The United States has a leading position in the worldwide with nearly 60 years of experience in developing satellite technology which pioneered by NASA.

Turkey with the first satellite ground station in 1979 sent BILSAT observation satellite which co-produced with foreign contractors into space from Russia in 2003. RASAT is the first observation satellite made in Turkey with its own design and the local production that sent into space in the year of 2011, and the satellites of Gokturk-2 were sent in 2012. The Turksat-6 with the Turkey's first communication satellite which is produced by local engineers and designers that the signatures are thrown in 2014, and it is planned to be sent into space in 2020 (Web1).

Indeed, the US is ahead with 60 years of the satellite experience, which will be in place to detect as Turkey is still developing the satellite technology with approximately 10 years of experience in satellite.

2. National Positioning System: GPS system also referred as the Global positioning system was developed by the US in 1973; it has become fully operational with 24 satellites in 1994. It can be readily indicated that the US is the pioneer to the Global positioning technology in the world.

Lutfi Elvan who was the Transport, Maritime and Communications Minister of the Republic of Turkey, recently stated that the National Geolocation System has been started to be studied in order to have an improvement as an alternative to GPS (Web2).

The USA with 40 years of positioning system technology have the leading position in the world, and then followed by the EU with "Galileo" system, China with "Compass" system, the Russian Federation with "Glonass" system and India with "IRNSS" system (Web3).

Turkey can be expressed to be having the developing positioning system technology as it does not have a positioning system.

3. Laser Guided Bomb Technology: The laser-guided bombs (LGB) technology began to the works of R \& D by the US in 1962 as the first in the world and it has become operative in 1968. While LGB was used smallscale intervention in the conflict until the 1990s, and it has been extensively used for the first time in Iraq Operation in 1991. The LGB were used instead of conventional ammunition of the all bombing missions which carried out by the United States within Kosovo operation in 1999 (Web4). The US with 50 years of experience, is leading the LGB technology.

As the ROKETSAN Company started to have the mass production in 2010, Turkey made a transition into the LGB technology with the Cirit (Javelin) rockets and has developed himself more with the UMTAS project and 
now, it can be expressed to be included in a rare category of the few governments to have this technology in the world (Web5).

4. Supercomputing Infrastructure: The countries are required to have the supercomputers in the military terms, due to whether the needs of the future of manned and unmanned systems to be managed by a senior network systems for the war will be conducted in the future or the great expectations of the information dimension may come to the main command center from the manned / unmanned systems.

Nowadays, supercomputers makes hundreds trillion operations per second. For example, as of June 2013, the supercomputer called as Tianhe- 2 in the China, has 3 million 120 thousand core and is capable of 33.86 quadrillion operations per second (Web6).

The US has the concept of the "Network Centric Operations" in which the command and control of the manned and unmanned systems can be blended in one hand. The powerful supercomputers are needed to create this concept.

According to the sites of top500.org that evaluates the processing capacity of supercomputers worldwide, as of 2013, there are 264 supercomputers from the US in the fastest 500 supercomputers list (Web7). There are no any supercomputers from Turkey entered into this list yet.

5. The Stages of Unmanned in the Military Area: As noted above, the United States is in the stage of using unmanned systems with the full autonomy which is in 5th stage regarding the unmanned military field. Even though the systems with full autonomy are not widely used in The United States yet, but they still continue to do their R \& D studies nonstop in this regard.

Turkey is in the stage of using the laser-guided bombs as a complementary element that is considered to be the 3th stage regarding the unmanning system and just stepped into the early stages of the variation of unmanned processes with the surface of the unmanned marine vehicles and the wheeled UGV produced as a prototype by a few civil-companies such as Global Inc. and etc.

6. In the Unmanning field which country to give importance to: The US is taken as an example by other countries regarding the unmanning field in the world, and is the country sets standards related to the unmanned land, the air and the marine systems. In addition, the government is successfully continuing the triangle of government, the private sector and the universities.

Turkey began the projects regarding the unmanning in the military field through the Undersecretariat of Defense Industry in the 1990s. The projects which focus on the air systems show itself with the propellers and the rotors UAVs. According to the Turkey's roadmap of UAV Systems in 2011-2030, the unmanned combat aircraft is planned to be produced by 2030 (Web8). The studies regarding the unmanned system of the land and the sea that stands out as the lack of Turkey.

7. The Stages of Infantry's Assignment in the Battlefield: The US has approximately 40 years of professional experience in the infantry units as making the transition from the compulsory military service into the professional military services in 1973 followed by the Vietnam War. Indeed, as the studies of recent years carried out in the near future, they plan to make a transition into the unity of the "hybrid infantry" which consists of mixed human and robotic in parallel with the development of the unmanned land vehicles.

In Turkey, where compulsory military service is still in force, the studies of making a transition into the professional military services is still continuing (Akyurek, 2010).

\section{CONClusion}

As a result, the United States is considered of maintaining its feature for being only one in the world with a significant amount in the budget to be set aside for critical investments and a significant amount of the budget allocated for the unmanned facilities of the military field. Therefore, the United States sets the standards for the future of the studies in the relevant subject. Other governments are trying to take the US as their model due to these features. Turkey is not at the desired level even though working on it step by step in these areas. Financial resources are not allocated enough for this type of studies as required. As the studies in Turkey are concentrated only on UAVs, there is virtually no area of the land and the sea. The professionalism feature of the Turkish army is not enough. Not only will the transition into a hybrid structure-military in which creating the likely robot by other governments become easier in the future, but the qualified staff also use the unmanned technology on the air as well as the land easier.

When considered from an economic perspective, As a result of the transition from the mass armies into hybrid structure, the staff and maintenance costs will be easily able to be saved, and the young and dynamic population of military age economy will continue to be in the workforce wheel. When the subject is viewed from the social 
perspective, rupture of the social life of the citizens who called for troops to be blocked and the possible discontent against the staff casualties or the public opinion may occur in any war can be minimized in the future.

Turkey should do strategic plans, government-industry and provide better coordination in the university context, and use resources sparingly, despite its appearance of the superior compared with other governments in the region. Turkey's progress in this area, the state will recover from the heavy economic burden, and therefore more visible in the region and will be an actor in the global arena.

\section{REFERENCES}

[1] Akyürek S., (2010), "Zorunlu Askerlik ve Profesyonel Ordu", Teknik Rapor No:24, BİLGESAM.

[2] ARLTAB (Army Research Laboratory Technical Assessment Board), (2011), "2009-2010 Assessment of the Army Research Laboratory", Technical Report ISBN: 978-0-309-21140-6, National Research Council, Washington, D.C., USA.

[3] BAST (Board on Army Science and Technology), (2002), "Technology Development for Army Unmanned Ground Vehicles", Technical Report ISBN: 0-309-50365-5, Committee on Army Unmanned Ground Vehicle Technology, National Research Council, Washington, D.C., USA, pp. 3,105.

[4] BAST (Board on Army Science and Technology), (2013), "Making the Soldier Decisive on Future Battlefields", Technical Report ISBN: 978-0-309-28453-0, Committee on Making the Soldier Decisive on Future Battlefields, Division on Engineering and Physical Sciences, National Research Council, Washington, D.C., USA, pp. 77, 115, 198.

[5] Bessemer W. G., (2006), "Transitioning to Unmanned Combat Aerial Vehicles", The Master Thesis, Naval Postgraduate School, California, USA, p. 1.

[6] Chiang E., Wrightson P., (2012), "Intelligent Human-Machine Collaboration: Summary of a Workshop", Technical Report ISBN: 0-309-66123-4, Board on Global Science and Technology, Policy and Global Affairs, National Research Council, Washington, D.C., USA, p. 23.

[7] Guest J., (2011), "Advancing Weapons Technology and the Future of Warfare: Strategic, Legal and Ethical Perspectives", The Master Thesis, University of Canterbury, England.

[8] Jones J. P., (2009), "Cooperative Area Surveillance Strategies Using Multiple Unmanned Systems", The Doctorate Thesis, Georgia Institute of Technology, USA, p. xv.

[9] Larkin M. S., (2011), "Brave New Warfare: Autonomy in Lethal UAVs", The Master Thesis, Naval Postgraduate School, California, USA, pp. 12, 47.

[10] Nader C. E., (2007), "An Analysis of Manpower Requirements for the United States Marine Corps Tiers II\&III Unmanned Aerial Systems Family of Systems Program", The Master Thesis, Naval Postgraduate School, California, USA.

[11] Neal P. J., (2010), "From Unique Needs to Modular Platforms", The Future of Military Robotics, pp. 1, $2,6$.

[12] Quintana E., (2008), "The Ethics and Legal Implications of Military Unmanned Vehicles", Royal United Services Institute for Defence and Security Studies, United Kingdom, p. 7.

[13] Sklar E., (2010), "Exploring Robotics", The Coursepack, Brooklyn College of the City University of New York, USA, pp. 39, 162 .

[14] Tsourveloudis N.C., Doitsidis L., Valavanis K.P., (2005), "Autonomous Navigation of Unmanned Vehicles: A Fuzzy Logic Perspective", In: V. Kordic, A. Lazinica, M. Merdan, "Cutting Edge Robotics", InTech, p. 306.

[15] Valois J. S., Herman H., Bares J., Rice D. P., (2009), "Remote Operation of the Black Knight Unmanned Ground Combat Vehicle", National Robotics Engineering Center, Carnegie Mellon University.

[16] Web1, http://www.sabah.com.tr/gundem/2014/12/15/ilk-milli-uyduda-imzalar-atildi (Access Date: 05.02.2015)

[17] Web2, http://www.aa.com.tr/tr/haberler/449350--gpse-alternatif-bir-sistem-kuracagiz (Access Date: 07.02.2015)

[18] Web3, http://global.britannica.com/EBchecked/topic/235395/GPS (Access Date: 14.02.2015)

[19] Web4, http://global.britannica.com/EBchecked/topic/406883/naval-warfare/53041/The-age-of-the-guided-missile (Access Date: 16.02.2015)

[20] Web5, http://www.milliyet.com.tr/iste-turkiye-nin-ilk-yerlitanksavarfuzesi/ekonomi/ekonomidetay/19.03.2013/1682 266/default.htm (Access Date: 18.02.2015)

[21] Web6, http://www.forbes.com /sites/ alexknapp/2014/06/23/ chinas-tianhe- 2-remains- the- worlds- fastest- super computer/ (Access Date: 10.03.2015)

[22] Web7, http://www.top500.org/statistics/list (Access Date: 16.02.2015)

[23] Web8, http://www.ssm.gov.tr/anasayfa/projeler/Sayfalar/projeler.aspx?projeGrubuID=7 (Access Date: 16.02.2015) 
American Research Journal of Humanities and Social Sciences, Volume 1, Issue 4, 2015

ISSN 2378-7031

[24] Yuqiao Z., (2009), "AM 17 Field Ruggedized UGV", The Master Thesis, National University of Singapore, Singapore, pp. $4-10$.

\section{AUTHORS' BIOGRAPHY}

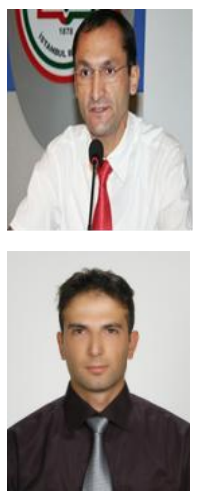

Ercan Karakoc is an Associate Professor at Yildiz Technical University (YTU) in Istanbul, Turkey. He received his MA from Strategy Science Department at Gebze Institute of Technology and earned his Ph.D. from History Department at Marmara University, Istanbul. His studies mainly focus on modern Turkish history. He has published nearly 20 articles and presentations.

Osman Yildiz is working as an officer in Turkish Armed Forces. He received his MA from Strategy Science Department at Gebze Technical University, Turkey. 